\title{
AN ORGANISATIONAL PERSPECTIVE ON SOCIAL EXCLUSION IN HIGHER EDUCATION: A CASE STUDY
}

\section{Jelle Mampaey}

Open University of the Netherlands

jelle.mampaey@ou.nl

Ghent University

jelle.mampaey@ugent.be

\section{Abstract}

We explore organisational mechanisms underlying social exclusion in higher education, the latter defined as the underrepresentation of students from lower socio-economic backgrounds. We focus on "decoupling," which is a central concept in organisational institutionalism referring to the construction of gaps between public commitment and core organisational practices, a common phenomenon in organisations worldwide. In the context of social inclusion this implies that universities are often publicly committed to social inclusion whereas their actual practices reproduce social exclusion. Drawing on an in-depth case study of a Flemish university, we identify four possible antecedents of decoupling: institutional contradictions resulting from the neo-liberalisation of higher education, uncertainty about effective inclusive practices, resistance of key constituencies and resource stringency resulting from experiences of lacking public funding.

Keywords: decoupling; implementation; organisational perspective; public commitment; social exclusion

\section{INTRODUCTION}

Students from lower socio-economic backgrounds are still underrepresented in higher education worldwide, in spite of the so-called democratisation of higher education (e.g. Argentin and Triventi 2011; Davies and Guppy 1997; Groenez et al. 2009). Even when

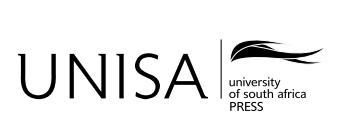

Education as Change www.educationaschange.co.za

Volume 21 | Number 3 | 2017 | \#1492 | 19 pages https://doi.org/10.17159/1947-9417/2017/1492 ISSN 1947-9417 (Online)

(C) 2017 The Author(s) 
they gain access, their completion rates are lower relative to other groups (e.g. Argentin and Triventi 2011; Blossfeld and Shavit 1993; Groenez et al. 2009) and when they do complete, their qualifications are often less valuable for they are mainly enrolled in institutions that yield lower returns on investment (e.g. Bastedo and Jaquette 2011; Monks 2000). Most studies explain this social exclusion by either referring to factors at the student level (e.g. Aina 2013; Ayalon 2007; Ball et al. 2002; Bastedo and Jaquette 2011; Belloc et al. 2010; Checchi et al. 2008; Devas 2011; Ellwood and Kane 2000; Frank and Cook 1995; McKenzie and Schweitzer 2001; Schindler and Lorz 2012; Tieben and Wolbers 2010) or factors at the system level (e.g. Ayalon 2007; Liu 2011; Naidoo 2004; Shavit et al. 2007; Triventi and Trivellato 2009). For instance, studies in the former cluster focus on inter-group differences in academic ability, cultural and social capital, and motivation. In the latter cluster, studies draw attention to the discriminatory nature of higher education systems. Bourdieu's concept of field has been applied to demonstrate that the field of higher education is a "sorting machine that selects students according to an implicit social classification" (Naidoo 2004, 459). It should however be noted that higher education is often conceptualised as a system maintaining (instead of causing) social exclusion that has already been instigated in earlier stages of students' educational careers (e.g. Lucas 2001; Raftery and Hout 1993).

In spite of this massive body of literature, the role of factors at the organisational level is underexplored. In a recent study it is however demonstrated that the idea of social inclusion has been embraced across the higher education sector, but its translation into inclusive practices is not yet apparent (O'Shea et al. 2016). This study echoes seminal work arguing that social inclusion is a dominant value in higher education (e.g. Clark 1983; North 2006), but it also demonstrates that public commitment to social inclusion may not always be translated into the core or actual practices of universities. Compared to the common practices in contemporary higher education, social inclusion requires radically different practices such as culturally-sensitive and student-centred teaching (including e.g. a less abstract language style excluding jargon), mentoring/tutoring, community-service learning, less selective student recruitment and evaluation, etc. (e.g. Agirdag 2010; Demie 2005; Reed et al. 2015; Scheurich 1998). For the remainder of this article, we refer to these alternative practices as inclusive practices, which are broader than teaching and learning practices in that they also include e.g. less selective student recruitment policies, financial support and study guidance provided by the institution, developing an organisational culture of care for individual students, etc. Crucially, when social inclusion is not translated into inclusive practices, universities remain highly inaccessible and reproduce social exclusion, even though they may be publicly committed to social inclusion. Hence, one may question the impact of universities' commitment to social inclusion. Our research question is: why is public commitment to social inclusion not necessarily translated into inclusive practices of universities? We have not been able to identify studies that address these (or similar) research questions, except for the recent study mentioned above. O'Shea and colleagues (2016) refer to 
the perceptions of academic staff who may be resistant to social inclusion. In specific, they demonstrate that deficit discourses of academic staff inhibit the implementation of inclusive practices.

We aim to contribute to this literature by exploring antecedents of this failure of implementation beyond perceptions of academic staff, although in line with the study of O'Shea and colleagues (2016) we also find that this factor is important (see below). To approach our research question theoretically, we draw on organisational institutionalism, a sociological perspective on organisations. In organisational institutionalism, the phenomenon of building gaps between public commitment and core organisational practices is referred to as "decoupling" (Meyer and Rowan 1977), even though it should also be noted that this is not necessarily an intentional strategy (Gondo and Amis 2013). In specific, we draw on a recent study that theorises the antecedents of decoupling (Rasche and Gilbert 2015) to build our theoretical framework that is used as a lens to collect and analyse our data. Empirically, we explore the antecedents of decoupling in an in-depth case study of a Flemish university.

The paper is structured as follows. In the following section, we present the theoretical framework that was used to collect and analyse our data. Thereupon, we describe the research design. We conclude with the presentation of our findings and a discussion of the relevance of our perspective for future research on social exclusion in higher education.

\section{THEORETICAL FRAMEWORK: THE ANTECEDENTS OF DECOUPLING}

Organisational institutionalism is a sociological perspective that supports us to theorise organisational responses to dominant values, as well as their antecedents (see Greenwood et al. 2008 for an overview). In specific, we draw on the recent study of Rasche and Gilbert (2015) that integrates insights from earlier research on the antecedents of decoupling. Organisations (including universities) are part of an organisational field (a community of interrelated organisations) in which certain values, norms, rules and conventions are dominant. For instance, in the organisational field of business schools, corporate responsibility is a dominant value. Each individual business school is strongly pressured to comply with the dominant value in order to gain and maintain legitimacy, hence earn the right to exist in the organisational field. That being said, organisations do not necessarily implement the dominant values in their core organisational practices. On the contrary, they often (un)intentionally build gaps between their public commitment to the dominant values and their core organisational practices (i.e. decoupling). Via decoupling, organisations can gain and maintain legitimacy while at the same time maintaining internal flexibility (see also Meyer and Rowan 1977). In the example of the business schools this would mean that they are publicly committed to the dominant value of corporate responsibility but at the same time their organisational practices do 
not reflect (or even contradict) the value. A related example is a company that actually pollutes the environment, but claims to value corporate responsibility in its external communication, e.g. in its marketing campaigns.

Rasche and Gilbert (2015) identify four antecedents of decoupling. Each of the antecedents increases the likelihood of decoupling (i.e. sufficient but not necessary conditions), hence it could also be argued that a joint occurrence is related to the highest likelihood. First, decoupling is likely to occur in organisational fields characterised by institutional contradictions. In these fields, organisations are subjected to competing values (e.g. responsible versus irresponsible management), making it hard to implement them both. Organisations often respond by implementing one of the values while decoupling the other. Consequently, organisations rhetorically adhere to both competing values but actually implement only one of them. Second, the likelihood of decoupling also increases when organisations are uncertain about the practices that are needed to make the dominant value happen. This uncertainty especially occurs when the dominant value is (perceived to be) ambiguous. Ambiguous, broadly formulated values (e.g. corporate responsibility) give organisations room to manoeuvre. More specifically, organisations can negotiate how to implement ambiguously formulated values. In the most extreme case, they can even argue that no or incremental changes to existing practices are sufficient to implement the dominant value. Hence, ambiguously formulated values make it easy for organisations to decouple public commitment to the dominant value from actual implementation.

The other two antecedents are situated at the intra-organisational level. In specific, the likelihood of decoupling increases when key constituencies overtly or covertly resist the dominant value (see also Gondo and Amis 2013). In cases where powerful actors have no interest in implementation, for instance because they conceive of implementation as conflicting with personal interests, they may decouple public commitment from core organisational practices. Decoupling especially occurs when actors do not see the need for change and when they have the power to avoid implementation. Finally, decoupling is likely to occur when organisations experience resource stringency. Implementation processes require resources including financial and non-financial (e.g. time, expertise) resources. Hence the implementation of a (new) dominant value reduces the available resources. In the case of scarce resources, implementation processes may be conceived of as conflicting with the efficient allocation of resources. Contemporary organisations (especially public ones) often experience resource stringency because of widespread cuts in public funding and increasing competition, which increases the likelihood of decoupling.

\section{METHODOLOGY: A CASE STUDY}

The institutional context of our empirical study is the Flemish higher education system in the northern region of Belgium, with five traditional universities, 17 university 
colleges and one transnational university (the landscape is continuously changing due to multiple merger operations). In this system, the underrepresentation of students from lower socio-economic backgrounds is extreme (Hirtt et al. 2007). Students from lower socio-economic backgrounds are underrepresented in higher education and when they do enrol they often drop out without graduation. For instance, it has been demonstrated that the likelihood of graduation is about four times lower for students from lower socio-economic backgrounds (Groenez et al. 2009). Consequently, since the early 2000s, the government has been stimulating universities (and other higher education institutions) to reduce social exclusion in higher education. The value of social inclusion is increasingly important and this value is often associated with other values such as student diversity and equal opportunities. In the Flemish higher education context, these values are often used interchangeably (Mampaey, Huisman, and Seeber 2015). The governmental pressures seem to have had a slightly positive effect at the system level. Over the last years preceding our study, the absolute number of financially supported students (the best available indicator of lower socio-economic background in Flemish higher education) has been slightly increasing at the system level, ranging from 41.720 in 2008-2009 to 47.173 in 2012-2013. The relative number has been quite stable, ranging from 22 per cent in 2008-2009 to 21 per cent in 2012-2013.

Our research question is an explorative why-question in a real-life setting, making qualitative case-study research suitable (Yin 2009). This is an established methodology in the field of higher education. Such a design is focused on theory building in new research areas. As we aim for an explorative, in-depth investigation of decoupling and its antecedents, we opted for a single case-study design. To select our case, we drew on the principle of "theoretical sampling" (Guba 1981), which means that we selected the case based on theoretical rather than statistical considerations. The selected university is a publicly funded, research-intensive university located in a medium-sized city in Flanders. Since the beginning of the century associations have been formed between research-intensive universities and university colleges (University X Association). These associations have multiple goals including increasing quality, transparency (of the programmes) and student diversity. It should be noted that there are no strong barriers to increasing student diversity at the system level. The tuition fee is about 600 Euro per year, which is relatively low compared to other countries. Additionally, students from lower socio-economic backgrounds (which is measured based on family income) receive financial support from the state. There are no entry examinations hence all students are free to enrol if they have a certificate of secondary education (or high school). Crucially, we selected a university which is renowned for its ambition to achieve social inclusion. At the same time, this case apparently struggles with the successful education of students from lower socio-economic backgrounds: their absolute and relative numbers are slowly decreasing (see Table 1). At the system level, the absolute number has been slightly increasing and the relative number has been quite stable (see above), in contrast to the pattern in our case. Hence, the selected university is an exception in a negative 
sense. Given that this evolution is exceptional compared to the system level, we assume that this evolution is caused by exclusive processes at the organisational level. Hence, this pattern may be an indicator that the public commitment to social inclusion is not reflected in inclusive practices.

Table 1: Evolution of the number of students receiving governmental financial support (first row). In Flanders, children from low-income families receive this type of support, hence it is a proxy for (the number of students from) lower socio-economic backgrounds.

\begin{tabular}{|l|l|l|l|l|l|}
\hline & 2008-2009 & 2009-2010 & 2010-2011 & 2011-2012 & 2012-2013 \\
\hline University X & $\begin{array}{l}332(20 \%) \\
\text { total = 1.696 }\end{array}$ & $\begin{array}{l}314(17 \%) \\
\text { total = 1.841 }\end{array}$ & $\begin{array}{l}312(17 \%) \\
\text { total = 1.810 }\end{array}$ & $\begin{array}{l}\text { 307 (17\%) } \\
\text { total = 1.791 }\end{array}$ & $\begin{array}{l}\text { 287 (16\%) } \\
\text { total = 1.775 }\end{array}$ \\
\hline
\end{tabular}

Source: Data Warehouse Higher Education

The concepts identified in the theoretical framework (institutionalised values, public commitment, implementation, decoupling, institutional contradictions, uncertainty, resistance, resource stringency) guided the data collection process (November 2014 - September 2015), functioning as "sensitizing concepts" (Chamberlain 2006). We specifically explored the (antecedents of) organisational responses to the value of social inclusion. We collected data through an in-depth interview, meetings and documents (i.e. an interview with the diversity expert of the university, meetings with administrative and academic staff members, national policy documents, research papers, organisational policy documents such as websites, strategic plans and brochures, and informal meetings with Flemish academics and administrative staff members). Our open interview questions included topics such as the management of social inclusion, the history of the university, the constituencies and their support, and the actual policies and practices. We interviewed an experienced administrative staff member who was responsible for social inclusion and who was seen as the diversity expert of the university. We assumed that this staff member would have an accurate view on the social inclusion policies and practices of the university. We asked the interviewee to adopt a retrospective perspective on social inclusion, focused on the 15 years preceding the study. Furthermore, in the meetings, we informally discussed the university's approach to social inclusion (we spoke with 10 staff members). We explicitly aimed to combine data sources - both qualitative and quantitative - to allow us to triangulate data, increasing their reliability (Denzin 1970).

We opted for an "organizing strategy" (Langley 1999) to analyse the data, which means that we balanced between an inductive and a deductive approach. As we used this strategy, the resulting theory should be seen as hypothetical, which could be tested and expanded in future research. We used the identified concepts and assumptions in the theoretical framework to organise the data and develop a new theory (see also Eisenhardt 1989). 


\section{EVIDENCE OF DECOUPLING}

We found that the university claims to be inclusive in its external communication and the focus is broader than social inclusion. Consider for instance (parts of) the mission statements that we found on the website:

[University $\mathrm{X}]$ is an independent innovative university which is regionally anchored and has a pronounced international orientation. The university stands for excellence in education, top research in spearhead fields and active engagement in innovation and entrepreneurship. The overall objective is to combine academic excellence with economic and social relevance. The university aims to widen participation, addressing all talents, and inspires its students and staff to develop their full potential in a dynamic environment. (Mission statement University X)

Our [University X Association] ambition is characterized by the following objectives: ... further development of a diversity policy with the aim of maximizing participation of disadvantaged groups in higher education. (Mission statement University X Association)

Along with an emphasis on other central values in Flemish higher education such as academic excellence and economic relevance (see also Mampaey, Huisman, and Seeber 2015), reference is made to inclusion. The mission statement contains values such as widening participation, addressing all talents, the development of students' full potential and participation of disadvantaged students (including students from lower socio-economic backgrounds). In the Flemish context, these values are all related to the overarching value of inclusion (see Mampaey, Huisman, and Seeber 2015). We also found references to inclusion in other publicly available documents including the strategic plan and visible symbols, for instance a photo with a mixture of black and white students. Conspicuously, in the written documents the style of communication is not assertive (i.e. inclusion is not presented as an objective attribute of the organisation) but the university presents inclusion as an aim or ambition, hence inclusion is presented as an attribute of the future (see also Huisman and Mampaey 2016). This is already an indication that the university has not yet translated the idea of inclusion into their core organisational practices. The non-assertive style could also be identified in the interview, in which the diversity expert constructs inclusion as an ambition instead of an organisational reality:

The university conceives of inclusion as an important aim and as a characteristic of our diversity policy ... it should be inclusive. ... An inclusive policy means that anyone can develop its talents.

... We want to remove structural barriers given the observation that there are some deficits in certain groups. (Interview with diversity expert)

We also found more explicit evidence of decoupling. Some inclusive practices could be identified but the interviewee explicitly referred to the decoupling of the university in that it was argued that the adoption of inclusion at the level of actual practices is in its initial phase, although it should be noted that the value of inclusion was already introduced in the early 2000s: 
Our inclusive policy has only just begun ... it has no impact on the teaching practices yet ... it has no impact on our teaching staff ... there is a great openness ... it is not that we do nothing ... but it is still the beginning. ... The awareness of the importance of an inclusive policy has grown slowly. ... For the time being the focus is on ... creating openness for disadvantaged students ... through several actions. For instance, we make provision for students to be informed and we have tutoring projects. (Interview with diversity expert)

Hence, the university publicly commits itself to the value of inclusion in its external communication (e.g. through marketing campaigns, visible symbols, mission statements, strategic plans), but the public commitment is only partly reflected at the level of inclusive practices, which was also confirmed by informal meetings with other (former) staff members of the university. In this university inclusion is mainly reduced to tutoring and mentoring students from lower socio-economic backgrounds (but also other nontraditional students) whereas radical organisational change of actual practices is largely absent. That is, inclusive practices that have been identified in the literature (e.g. Agirdag 2010; Demie 2005; Reed et al. 2015; Scheurich 1998) —including less selective student recruitment and evaluation, an organisational culture of care, individually-centred teaching and learning (e.g. individual learning plans and support systems), culturallycentred teaching and learning (e.g. a multicultural curriculum, multilingual instruction) and related radical practices - could not be identified in this university.

\section{EVIDENCE OF THE ANTECEDENTS OF DECOUPLING}

We were able to identify all four antecedents of decoupling integrated in the theoretical model of Rasche and Gilbert (2015), which we present in the next four subsections. Rasche and Gilbert (2015) conceptualised the antecedents of decoupling in the context of corporate social responsibility in business schools. Based on our analysis, we were able to refine the specific nature of the four antecedents in the context of social exclusion in higher education.

\section{Institutional Contradictions Resulting from the Neo-Liberalisation of Higher Education}

We found strong evidence of an institutional contradiction in the scholarly literature, which was reaffirmed during informal meetings with academics and administrative staff members. Contradictory institutional demands are present in Flemish (higher) education where some constituencies expect universities to be selective, while others expect inclusion (see e.g. Mampaey and Zanoni 2014). This institutional contradiction is also tangible at the global level, which is for instance demonstrated by Shaw (2009):

The increasing pressure towards widening participation in higher education ... can be seen as either an opportunity or a threat. On the one hand it provides new opportunities for students to learn from and challenge one another ... On the other hand it requires changes in the way in 
which higher education is conceived of, developed and organized, and provides challenges to current practices of learning and teaching. These changes and challenges can lead to fears about lowering standards, and raises questions about whether diversifying the student body detracts from "excellence."

Apparently, in higher education worldwide there is a dominant discourse that constructs quality and inclusion as mutually exclusive values. The diversity expert did not refer to the institutional contradiction, but in the informal meetings with staff members, the crucial role of this contradiction was strongly emphasised and explicitly linked to the neo-liberalisation of higher education in the last decades, which is in line with established insights in the higher education literature (Marginson 2006a, 2006b; Meek 2000). In specific, it has already been argued that "academic capitalism" (Slaughter and Rhoades 2004) is a serious threat to the traditional idea of higher education as a public good and related values such as social inclusion, equality, democracy and the likes. In the context of our study, two specific mechanisms related to neo-liberalisation played an important role. One has to do with to the first antecedent of decoupling that we discuss here, the other is related to the fourth (see below).

Particularly, academic capitalism increases competition for organisational status (Mampaey, Huisman, and Seeber 2015; Marginson 2006a, 2006b). In turn, organisational status is strongly related to the perceived quality of education (Yang, Alessandri, and Kinsey 2008). A fundamental problem is that the perceived quality of education somehow contradicts with social inclusion in that student selectivity is an important proxy of the quality of education (Mampaey and Zanoni 2014; Marginson 2006a, 2006b; Zanoni and Mampaey 2013). Hence, in order to increase their organisational status, higher education institutions are incentivised to invest in their perceived quality of education through e.g. excellence initiatives (see e.g. Kottmann et al. 2016), selective student recruitment policies, etc. Accordingly, in a neo-liberal higher education system, higher education institutions will often prioritise the management of the perceived quality of education at the expense of the implementation of inclusive practices. This tension and the resulting prioritisation of the perceived quality of education was a dominant theme in the informal conversations with staff members. One of these staff members, a professor affiliated with business schools, argued that Flemish universities are strongly pressured to prioritise the acquisition of excellence labels such as EQUIS, often at the expense of other, more social purposes such as social inclusion.

\section{Uncertainty about Effective Inclusive Practices}

Second, we found that uncertainty is strongly embedded in Flemish macro-level policies. Institutional autonomy is one of the main characteristics of the steering context (Van Heffen et al. 1999; Verhoeven et al. 2005). Consequently, there is no formal policy document that identifies practices that are required to increase inclusion or guides their implementation. On the contrary, it could even be argued that Flemish universities have 
the leeway to avoid implementation in that it is not clarified which practices are needed to make inclusion happen. The uncertainty was emphasised in the interview with the diversity expert, who indicated that there is a lack of awareness about best practices enhancing inclusion:

In a recent workshop a Flemish professor was teaching about the abstract language style in our courses which is difficult to follow for socially disadvantaged students, but this was astonishing for our teachers. Our teachers are prepared to accept the idea of equal opportunities in higher education but they are not yet capable of translating this value into practice. (Interview with diversity expert)

\section{Resistance of Key Constituencies}

The university also perceives resistance to the value of social inclusion:

There are some deficits in certain groups.... Once you should come to our open day for Maghreb students. It is the Third World you see there. (Interview with diversity expert)

Interestingly, in this university students from lower socio-economic backgrounds themselves are seen as constituencies who resist inclusion because of their lack of motivation and skills. This finding is not surprising given the dominance of "deficit thinking" in Flemish higher education, in which students from lower socio-economic backgrounds are constructed as lacking motivation and skills to enrol and succeed, whereas the education system and the professionals are not held accountable for social exclusion (e.g. Mampaey and Zanoni 2016). We indeed found evidence that this university also passes responsibility to the students themselves, a process which may inhibit radical change of organisational practices. Although we did not find explicit evidence of perceived resistance of staff members, in the broader literature it has been demonstrated that top-down change processes are strongly resisted because they contradict academic freedom, as is for instance demonstrated by Rasche and Gilbert (2015):

[T] he importance ascribed to the concept of "academic freedom" and the inertia created by the tenure system are structural features that limit deans' influence on the curriculum. For instance, the tenure system can act as an obstacle to change, as tenured faculty face little pressure to rework course materials. Few professors want to be told by others what and how they are supposed to teach.

\section{Resource Stringency Resulting from Experiences of Lacking Public Funding}

Finally, the university experiences resource stringency. Similar to other European higher education systems, there is a tendency in Flanders to reduce public funding for 
universities and other higher education institutions. In particular, a specific funding programme to enhance social inclusion ("Aanmoedigingsfonds") has been cancelled at the time of our empirical study, but it should also be noted that this funding was extremely small (less than $0.5 \%$ ) compared to the total amount of public funding. Also, at the time of our empirical study, we witnessed a heated media debate on planned cuts in public funding in the near future. The diversity expert was aware of the (possible) reductions and even experienced a tension between the enrolment of students from lower socio-economic backgrounds and public funding.

This fourth antecedent may be the most important one in contemporary higher education, given that higher education institutions are increasingly confronted with resource stringencies due to the neo-liberalisation of higher education (Slaughter and Rhoades 2004). One of the fundamental arguments against this neo-liberalisation is that cuts in public funding inhibit social inclusion (see also Giroux 2002). In the Flemish context, cuts in public funding have however not been drastic in that expenditure per student has been relatively stable over the years. What has been cancelled is the specific funding programme to enhance social inclusion (see above) and the diversity expert explicitly stated that this situation has affected the approach to social inclusion in a negative way. It was argued that some of the initiatives (e.g. mentoring of/ study guidance for ethnic minority students) had to be cancelled as a result of this specific cut in public funding. It was also argued that much more money is needed to successfully educate socially disadvantaged students, but that the government rather threatens with cuts in public funding. Hence, an experienced and anticipated lack of funding (not necessarily a lack of objective funding) seem to affect the failure of implementation of inclusive practices at this university. That being said, in contemporary higher education, values associated with the idea of education as a public good are still strongly institutionalised (e.g. Mampaey, Huisman, and Seeber 2015) and higher education institutions are strongly pressured to comply with these values. One of our key arguments in this paper is that this dangerous cocktail creates the perfect situation for decoupling to occur. In specific, signalling compliance to institutionalised values through mere rhetoric (or even disguising actual non-compliance) is much cheaper compared to actually implementing an inclusive pedagogy and other inclusive practices. In this way, huge savings could be made, which fits with the neo-liberal logic of efficient supply. At the same time, by signalling compliance with institutionalised values, higher education institutions can maintain legitimacy, which remains a fundamental organisational resource in contemporary higher education (e.g. Mampaey and Huisman 2016; Mampaey, Huisman, and Seeber 2015). The result is however a gap between rhetoric and practice in that higher education institutions claim to value social inclusion in their external communication, but do not translate their rhetoric into internal inclusive practices. Evidence of this interpretation could be found in the interview with the diversity expert, as well as in the informal meetings with staff members, who explicitly argued that the translation of the value of social inclusion into practice is highly problematic due to the 
lack of financial resources. Again, given that objective cuts of public funding have been relatively small in this specific context, an experienced lack of financial resources may be more important as an antecedent of decoupling compared to an objective lack, but it should also be stressed that the neo-liberal climate may strengthen these experiences. In other words, the neo-liberal climate may activate concerns about efficient organising by saving time and money wherever possible. In such a context, decoupling between rhetoric and practice is a likely outcome, especially in the context of social inclusion.

\section{THE CONSEQUENCES OF DECOUPLING}

Even though our research design does not allow us to make strong statements about causality for it is mainly meant to build theory, we clearly find a strong relationship between decoupling and social exclusion. Indeed, we found evidence of decoupling in a university in which the total number of students from lower socio-economic backgrounds has been decreasing in the years preceding our empirical study. As a result of decoupling, it is likely that the lack of implementation of inclusive practices discourages students from lower socio-economic backgrounds to enrol and/or succeed in the university. It is especially likely that organisational processes play a role in this regard as our case contrasts with the system level. At the system level, the absolute and relative numbers of socially disadvantaged students have not been decreasing, so it is highly likely that the exceptional pattern in our case is caused by processes at the organisational level (see methodology).

\section{DISCUSSION}

This paper started from the observation that sociological studies on social exclusion in higher education systematically focus on the role of individual (student) or system level barriers. Our study introduces an alternative perspective on social exclusion in (higher) education by incorporating mechanisms at the organisational level (see also O'Shea et al. 2016). One underexplored organisational mechanism through which social exclusion is reproduced is decoupling, which refers to the fact that universities (and other higher education institutions) may build gaps between their public commitment (i.e. they claim to be socially inclusive) and actual practices (i.e. their actual practices reproduce social exclusion). Our findings indicate that universities deploy decoupling when there are institutional contradictions resulting from the neo-liberalisation of higher education, uncertainty about effective inclusive practices, resistance of key constituencies and resource stringency resulting from experiences of lacking public funding. That being said, our research design does not allow us to draw conclusions about the impact of the individual antecedents. Further quantitative research could be oriented to investigate (interactions between) the antecedents and their impact, as well as the role of alternative antecedents. 
We have argued that each antecedent increases the likelihood of decoupling and that a joint occurrence is associated with the highest likelihood. Given the universal nature of the antecedents, we would expect decoupling to be a widespread phenomenon. Indeed, the tension between quality on the one hand and social inclusion on the other is not only tangible in Flemish higher education (Shaw 2009), although it could also be argued that the strength of this tension varies across higher education systems. Even more, institutional contradictions are a characteristic of higher education systems in general (Frølich et al. 2013). Also, uncertainty about inclusive practices is quite universal as well, especially in Western education systems where professionals are not aware that culturally-sensitive education is necessary to enhance social inclusion (Mampaey and Zanoni 2016). Regarding the third antecedent, academics' resistance to change processes may especially occur in higher education systems in which academic freedom is considered important. Finally, (experiences of) resource stringency may also be quite universal given the worldwide tendency to cut public funding in higher education. Our analysis also indicates that the universal nature of these antecedents could be related to the worldwide neo-liberalisation of higher education in the last decades (Marginson 2006a, 2006b; Slaughter and Rhoades 2004). Accordingly, this macro-context may be key to explaining the widespread occurrence of decoupling in further studies. We have especially highlighted two specific mechanisms underlying the relationship between neo-liberalisation on the one hand and the decoupling between inclusive rhetoric and exclusive practices on the other hand. First, we have argued that neo-liberalisation encourages competition for organisational status and the implementation of inclusive practices runs counter to organisational activities to enhance organisational status including e.g. selective student recruitment. Second, implementing inclusive practices requires lots of organisational resources including time and money, but the neo-liberal climate rather sustains a philosophy of carefully and efficiently handling these resources, and saving time and money wherever possible. In such a climate, higher education institutions are given multiple incentives to exclude socially disadvantaged students through their internal practices. That being said, higher education institutions cannot openly communicate this exclusion in that this would result in a loss of organisational legitimacy. We have argued that, to counter this problem, higher education institutions engage in some kind of window dressing to keep signalling compliance with the institutionalised value of social inclusion, while at the same time maintaining internal flexibility in a competitive environment (see also Meyer and Rowan 1977).

This is not to say that universities intentionally deploy decoupling. Given the widespread diffusion of the value of social inclusion and the ever-strengthening criticism on social exclusion in higher education, the phenomenon of unintentional decoupling (Gondo and Amis 2013) may be more relevant to explain gaps between public commitment and implementation. Indeed, it may be argued that universities that intentionally deploy decoupling by making social inclusion claims while at once excluding students from lower socio-economic backgrounds intentionally through their 
actual practices will lose legitimacy in many higher education systems across the globe. Indirect evidence for the process of unintentional decoupling could also be found in the studies of Sara Ahmed, who pointed at the politics of documentation in the context of antiracism in higher education, a finding that is quite similar to our findings (e.g. Ahmed 2006). What this scholar has pointed out is that staff members end up "doing the document" instead of "doing the doing" when they engage with antiracism in higher education, although they do this with good intentions. By producing documents such as strategic plans, higher education institutions signal their commitment to reducing antiracism, but this commitment is rarely translated into practice. Analogously, we found evidence of commissive speech acts in our case (see also Huisman and Mampaey 2016), signalling commitment to social inclusion, and this discourse of commitment seems to be sufficient to please external stakeholders in that they do not criticise the university for its exclusive practices. From our perspective, in the long run, this vicious circle of "doing documents" is an important mechanism underlying the reproduction of social exclusion in higher education.

The negative conclusion of our study is that in contemporary universities (and other higher education institutions) in neo-liberal systems, everything is in place for decoupling to occur. Decoupling may give rise to the "illusion" (see Rasche and Gilbert 2015) that social inclusion is progressing while in reality social exclusion is reproduced. This conclusion could however shed new light on the mechanisms underlying the ongoing reproduction of social exclusion in (higher) education. In the past, sociologists of education have systematically investigated mechanisms at the system and micro levels, but based on our study we would argue that they may have been looking in the wrong place. New solutions should be focused on interventions at the organisational level in order to support universities in their implementation of inclusive practices. A more positive conclusion is that decoupling may in the long run lead to recoupling (Hallett 2010; Tilcsik 2010), which means that decoupling may initiate actual change of core practices. Recoupling especially occurs when organisations recruit new organisational members to implement the new practices and when the new members have the knowledge and skills to make the implementation happen (Tilcsik 2010).

Our study points at organisational mechanisms underlying the reproduction of social exclusion in higher education, as well as how this reproduction could be counteracted. In this paper we focused on (the antecedents and consequences of) decoupling, but it should be noted that organisational institutionalism is a highly complex metaperspective containing multiple concepts and theories. Future research might take stock of other organisational mechanisms. For instance, organisational responses depend on translation processes (Sahlin and Wedlin 2008). The material context of an organisation (e.g. tradition, culture, identity) is a filter that affects how macro-level pressures are interpreted and framed, which could have strong implications for organisational responses. From this perspective, each university may have an idiosyncratic approach to social inclusion that does not necessarily lead to higher levels of access and/or 
completion for students from lower socio-economic backgrounds. Other relevant concepts with which to approach our research questions are strategic ambiguity, which refers to the vague and meaningless reformulation of macro-level pressures to please conflicting stakeholder groups (Giroux 2006), and strategic balance, which implies that organisations have an inherent need to differentiate their responses to macro-level pressures to be able to compete in the market (Deephouse 1999).

Our study has some limitations. Obviously, our case study was not meant to generalise our findings at the (inter)national level, although we would assume that organisational mechanisms (including decoupling) play an important role across the globe. Future research could build on our initial insights and investigate the impact of a wider range of organisational mechanisms in a wider sample of universities.

\section{REFERENCES}

Agirdag, O. 2010. "Exploring Bilingualism in a Monolingual School System: Insights from Turkish and Native Students from Belgian Schools." British Journal of Sociology of Education 31 (3): 307-21. https://doi.org/10.1080/01425691003700540

Ahmed, S. 2007. "'You End Up Doing the Document Rather Than Doing the Doing': Diversity, Race Equality and the Politics of Documentation." Ethnic and Racial Studies 30 (4): 590-609. https://doi.org/10.1080/01419870701356015

Aina, C. 2013. "Parental Background and University Dropout in Italy." Higher Education 65 (4): 43-56. https://doi.org/10.1007/s10734-012-9554-Z

Argentin, G., and M. Triventi. 2011. "Social Inequality in Higher Education and Labour Market in a Period of Institutional Reforms: Italy, 1992-2007." Higher Education 61 (3): 309-23. https://doi.org/10.1007/s10734-010-9379-6

Ayalon, H. 2007. “College Application Behavior: Who Is Strategic? Does It Help?" Higher Education, no. 54, 885-905. https://doi.org/10.1007/s10734-006-9031-7

Ball, S. J., J. Davies, M. David, and D. Reay. 2002. ““Classification' and 'Judgement': Social Class and the 'Cognitive Structures' of Choice of Higher Education." British Journal of Sociology of Education 23 (1): 51-72. https://doi.org/10.1080/01425690120102854

Bastedo, M., and O. Jacuette. 2011. "Running in Place: Low-Income Students and the Dynamics of Higher Education Stratification." Educational Evaluation and Policy Analysis 33 (3): 318-39. https://doi.org/10.3102/0162373711406718

Belloc, F., A. Maruotti, and L. Petrella. 2010. "University Drop-Out: An Italian Experience." Higher Education 60 (2): 127-38. https://doi.org/10.1007/s10734-009-9290-1

Blossfeld, A., and Y. Shavit. 1993. Persistent Inequality: Changing Educational Attainment in Thirteen Countries. Boulder: Westview Press. 
Chamberlain, G. P. 2006. "Researching Strategy Formation Process: An Abductive Methodology." Quality and Quantity 40 (2): 289-301. https://doi.org/10.1007/s11135-005-8094-3

Checchi, D., C. V. Fiorio, and M. Leonardi. 2008. "Intergenerational Persistence in Educational Attainment in Italy." IZA Discussion Paper 3622. Accessed October 13, 2017. https://papers.ssrn.com/sol3/papers.cfm?abstract_id=1198692

Clark, B. R. 1983. The Higher Education System: Academic Organization in Cross-National Perspective. Berkeley: University of California Press.

Davies, S., and N. Guppy. 1997. "Fields of Study, College Selectivity, and Student Inequalities in Higher Education." Social Forces 75 (4): 1417-438. https://doi.org/10.1093/sf/75.4.1417

Deephouse, D. L. 1999. "To Be Different, or To Be the Same? It's a Question (and Theory) of Strategic Balance." Strategic Management Journal 20 (2): 147-66. https://doi.org/10.1002/(SICI)1097-0266(199902)20:2<147::AID-SMJ11>3.0.CO;2-Q

Demie, F. 2005. "Achievement of Black Caribbean Pupils: Good Practice in Lambeth Schools." British Educational Research Journal 31 (4): 481-508. https://doi.org/10.1080/01411920500148705

Denzin, N. K. 1970. The Research Act: A Theoretical Introduction to Sociological Methods. Chicago: Aldine.

Devas, A. 2011. "Widening Participation and the Media Student Experience." Higher Education 62 (6): 815-28. https://doi.org/10.1007/s10734-011-9421-3

Eisenhardt, K. M. 1989. "Building Theories from Case Study Research.” Academy of Management Review 14 (4): 532-50. https://doi.org/10.2307/258557

Ellwood, D. T., and T. J. Kane. 2000. "Who Is Getting a College Education? Family Background and the Growing Gaps in Enrollment." In Securing the Future: Investing in Children from Birth to College, edited by S. Danziger and J. Waldfogel, 283-324. New York: Russell Sage.

Frank, R. H., and P. J. Cook. 1995. The Winner-Take-All Society: Why the Few at the Top Get So Much More Than the Rest of Us. New York: Free Press.

Frølich, N., J. Huisman, S. Slipersæter, B. Stensaker, and P. C. P. Botas. 2013. "A Reinterpretation of Institutional Transformations in European Higher Education: Strategizing Pluralistic Organizations in Multiplex Environments." Higher Education 65 (1): 79-93. https://doi.org/10.1007/s10734-012-9582-8

Giroux, H. 2002. "Neoliberalism, Corporate Culture, and the Promise of Higher Education: The University as a Democratic Public Sphere." Harvard Educational Review 72 (4): 425-64. https://doi.org/10.17763/haer.72.4.0515nr62324n71p1

Giroux, H. 2006. “'It Was Such a Handy Term': Management Fashions and Pragmatic Ambiguity.” Journal of Management Studies 43 (6): 1227-260. https://doi.org/10.1111/j.1467-6486.2006.00623.x

Gondo, M. B., and J. M. Amis. 2013. "Variations in Practice Adoption: The Roles of Conscious Reflection and Discourse." Academy of Management Review 38 (2): 229-47. https://doi.org/10.5465/amr.2010.0312 
Greenwood, R., C. Oliver, R. Suddaby, and K. Sahlin-Andersson. 2008. The Sage Handbook of Organizational Institutionalism. Thousand Oaks: Sage Publications.

Groenez, S., I. Nicaise, and K. De Rick. 2009. “De Ongelijke Weg Door het Onderwijs." In De Sociale Staat van Vlaanderen, edited by L. Vanderleyden, M. Callens and J. Noppe, 33-67. Brussel: Studiedienst van de Vlaamse Regering.

Guba, E. G. 1981. "Criteria for Assessing the Trustworthiness of Naturalistic Inquiries." Educational Communication and Technology: A Journal of Theory, Research, and Development 29 (2): 75-91.

Hallett, T. 2010. "The Myth Incarnate: Recoupling Processes, Turmoil, and Inhabited Institutions in an Urban Elementary School." American Sociological Review 75 (1): 52-74. https://doi.org/10.1177/0003122409357044

Hirtt, N., I. Nicaise, and D. De Zutter. 2007. De School van de Ongelijkheid. Antwerpen: EPO.

Huisman, J., and J. Mampaey. 2016. "The Style It Takes: How Do UK Universities Communicate Their Identity through Welcome Addresses?” Higher Education Research and Development 35 (3): 502-15. https://doi.org/10.1080/07294360.2015.1107889

Kottmann, A., J. Huisman, L. Brockerhoff, L. Cremonini, and J. Mampaey. 2016. "How Can One Create a Culture for Quality Enhancement?" Final report. Ghent University. Accessed October 16, 2017. http://hdl.handle.net/1854/LU-8129635

Langley, A. 1999. "Strategies for Theorizing from Process Data.” Academy of Management Review 24 (4): 691-710. https://doi.org/10.2307/259349

Liu, A. 2011. "Unraveling the Myth of Meritocracy within the Context of US Higher Education." Higher Education 62 (4): 383-97. https://doi.org/10.1007/s10734-010-9394-7

Lucas, S. R. 2001. "Effectively Maintained Inequality: Education Transitions, Track Mobility, and Social Background Effects." American Journal of Sociology 106 (6): 1642-690. https://doi.org/10.1086/321300

Mampaey, J., J. Huisman, and M. Seeber. 2015. "Branding of Flemish Higher Education Institutions: A Strategic Balance Perspective." Higher Education Research and Development 34 (6): 1178-191. https://doi.org/10.1080/07294360.2015.1024634

Mampaey, J., and J. Huisman. 2016. "Branding of UK Higher Education Institutions: An Integrated Perspective on the Content and Style of Welcome Addresses." Recherches Sociologiques et Anthropologiques 47 (1): 133-48.

Mampaey, J., and P. Zanoni. 2014. "Managing Legitimacy in the Educational Quasi-Market: A Study of Ethnically Diverse, Inclusive Schools in Flanders." British Educational Research Journal 40 (2): 353-72. https://doi.org/10.1002/berj.3087

Mampaey, J., and P. Zanoni. 2016. "Reproducing Monocultural Education: Ethnic Majority Staff's Discursive Constructions of Monocultural School Practices." British Journal of Sociology of Education 37 (7): 928-46. https://doi.org/10.1080/01425692.2014.1001059 
Marginson, S. 2006a. "Dynamics of National and Global Competition in Higher Education." Higher Education 52 (1): 1-39. https://doi.org/10.1007/s10734-004-7649-x

Marginson, S. 2006b. "Engaging Democratic Education in the Neoliberal Age." Educational Theory 56 (2): 205-19. https://doi.org/10.1111/j.1741-5446.2006.00012.x

McKenzie, K., and R. Schweitzer. 2001. "Who Succeeds at University? Factors Predicting Academic Performance in First Year Australian University Students." Higher Education Research and Development 20 (1): 21-33. https://doi.org/10.1080/07924360120043621

Meek, V. L. 2000. "Diversity and Marketisation of Higher Education: Incompatible Concepts?" Higher Education Policy 13 (1): 23-39. https://doi.org/10.1016/S0952-8733(99)00030-6

Meyer, J. W., and B. Rowan. 1977. "Institutional Organizations: Formal Structure as Myth and Ceremony." American Journal of Sociology 83 (2): 340-63. https://doi.org/10.1086/226550

Monks, J. 2000. "The Returns to Individual and College Characteristics: Evidence from the National Longitudinal Survey of Youth." Economics of Education Review 19 (3): 279-89. https://doi.org/10.1016/S0272-7757(99)00023-0

Naidoo, R. 2004. "Fields and Institutional Strategy: Bourdieu on the Relationship Between Higher Education, Inequality and Society." British Journal of Sociology of Education 25 (4): 457-71. https://doi.org/10.1080/0142569042000236952

North,C.E.2006."More than Words? Delving intothe SubstantiveMeaning(s)of 'Social Justice'inEducation." Review of Educational Research 76 (4): 507-35. https://doi.org/10.3102/00346543076004507

Oliver, C. 1991. "Strategic Responses to Institutional Pressures." Academy of Management Review 16 (1): 145-79.

O’Shea, S., P. Lysaght, J. Roberts, and V. Harwood. 2016. "Shifting the Blame in Higher Education -Social Inclusion and Deficit Discourses." Higher Education Research and Development 35 (2): 322-36. https://doi.org/10.1080/07294360.2015.1087388

Pache, A. C., and F. Santos. 2010. "When Worlds Collide: The Internal Dynamics of Organizational Responses to Conflicting Institutional Demands." Academy of Management Review 35 (3): 455-76. https://doi.org/10.5465/AMR.2010.51142368

Rasche, A., and D. U. Gilbert. 2015. "Decoupling Responsible Management Education: Why Business Schools May Not Walk Their Talk.” Journal of Management Inquiry 24 (3): 239-52. https://doi.org/10.1177/1056492614567315

Raftery, A. E., and M. Hout. 1993. "Maximally Maintained Inequality: Expansion, Reform and Opportunity in Irish Education, 1921-1975." Sociology of Education 66 (1):41-62.https://doi.org/10.2307/2112784

Reed, R., A. King, and G. Whiteford. 2015. "Re-Conceptualising Sustainable Widening Participation: Evaluation, Collaboration and Evolution." Higher Education Research and Development 34 (2): 383-96. https://doi.org/10.1080/07294360.2014.956692

Sahlin, K., and L. Wedlin. 2008. "Circulating Ideas: Imitation, Translation and Editing." In The Sage Handbook of Organizational Institutionalism, edited by R. Greenwood, C. Oliver, K. Sahlin and R. Suddaby. London: Sage. https://doi.org/10.4135/9781849200387.n9 
Scheurich, J. J. 1998. "Highly Successful and Loving, Public Elementary Schools Populated Mainly by Low-Ses Children of Color; Core Beliefs and Cultural Characteristics." Urban Education 33 (4): 451-91. https://doi.org/10.1177/0042085998033004001

Schindler, S., and M. Lorz. 2012. "Mechanisms of Social Inequality Development: Primary and Secondary Effects in the Transition to Tertiary Education between 1976 and 2005." European Sociological Review 28 (5): 647-60. https://doi.org/10.1093/esr/jcr032

Shavit, Y., R. Arum, and A. Gamoran. 2007. Stratification in Higher Education. A Comparative Study. Stanford: Stanford University Press.

Shaw, J. 2009. “The Diversity Paradox: Does Student Diversity Enhance or Challenge Excellence?” Journal of Further and Higher Education 33 (4): 321-31. https://doi.org/10.1080/03098770903266018

Siegel, D. J. 2006. "Organizational Responses to the Demand and Expectation for Diversity." Higher Education 52 (3): 465-86. https://doi.org/10.1007/s10734-006-0001-x

Slaughter, S., and G. Rhoades. 2004. Academic Capitalism and the New Economy: Markets, State, and Higher Education. Baltimore: Johns Hopkins University Press.

Tieben, N., and M. H. J. Wolbers. 2010. "Transitions to Post-Secondary and Tertiary Education in the Netherlands: A Trend Analysis of Unconditional and Conditional Socio-Economic Background Effects." Higher Education 60 (1): 85-100. https://doi.org/10.1007/s10734-009-9289-7

Tilcsik, A. 2010. "From Ritual to Reality: Demography, Ideology, and Decoupling in a PostCommunist Government Agency." Academy of Management Journal 53 (6): 1474-498. https://doi.org/10.5465/AMJ.2010.57318905

Triventi, M., and P. Trivellato. 2009. "Participation, Performance and Inequality in Italian Higher Education in the 20th Century. Evidence from the Italian Longitudinal Household Survey." Higher Education 57 (6): 681-702. https://doi.org/10.1007/s10734-008-9170-0

Valencia, R. 1997. The Evolution of Deficit Thinking: Educational Thought and Practice. London: Falmer.

Van Heffen, O., P. Maassen, J. Verhoeven, F. D. Vijlder, and K. D. Wit. 1999. Overheid, Hoger Onderwijs en Economie. Ontwikkelingen in Nederland en Vlaanderen. Utrecht: Lemma.

Verhoeven, J. C., G. Kelchtermans, and K. Michielsen. 2005. McOnderwijs in Vlaanderen. Inernationalisering en Commercialisering van het Hoger Onderwijs. Mechelen: Wolters Plantyn.

Westphal, J. D., and E. J. Zajac. 2001. "Decoupling Policy from Practice: The Case of Stock Repurchase Programs.” Administrative Science Quarterly 46 (2): 202-28. https://doi.org/10.2307/2667086

Yang, S. U., S. W. Alessandri, and D. F. Kinsey. 2008. "An Integrative Analysis of Reputation and Relational Quality: A Study of University-Student Relationships.” Journal of Marketing for Higher Education 18 (2): 145-70. https://doi.org/10.1080/08841240802487353

Yin, R. K. 2009. Case Study Research: Design and Methods. Thousand Oaks: Sage.

Zanoni, P., and J. Mampaey. 2013. “Achieving Ethnic Minority Students' Inclusion: A Flemish School's Discursive Practices Countering the Quasi-Market Pressure to Exclude." British Educational Research Journal 39 (1): 1-21. 